\title{
RENDIMENTO DE CARCAÇA E QUALIDADE DE CARNE DE CODORNAS MACHO PARA POSTURA
}

\author{
SILVA, Janaina Della Torre da ${ }^{1}$ \\ SILVA, Vanessa Karla ${ }^{2}$ \\ SILVA, Aline Mary Scatolini ${ }^{3}$ \\ BOIAGO, Marcel Manente ${ }^{4}$ \\ GRAVENA, Rodrigo Antonio 5 \\ MARQUES, Rafael Henrique ${ }^{6}$ \\ DIAS, Luciana Thie Seki ${ }^{7}$ \\ BORBA, Hirasilv ${ }^{8}$ \\ MORAES, Vera Maria Barbosa de ${ }^{9}$
}

\begin{abstract}
RESUMO: Tendo o objetivo de avaliar o desempenho, o rendimento de carcaça e a composição química da carne de codornas japonesas macho submetidas a diferentes níveis de energia e proteína na dieta, 216 codornas foram distribuídas em nove tratamentos, quatro repetições e seis aves por parcela. Aos 38 dias de idade as aves foram distribuídas em delineamento inteiramente casualizado, em esquema fatorial 3 x 3 , sendo três níveis de energia $(2.600,2.800$ e $3.000 \mathrm{kcal} \mathrm{EM} / \mathrm{kg})$ e três níveis de proteína $(16,18$ e 20\%), constituindo as rações experimentais fornecidas até 56 dias de idade. Os resultados mostraram que a matéria seca original foi significativamente mais elevada na carne das aves submetidas ao tratamento contendo $2.600 \mathrm{kcal} \mathrm{EM} / \mathrm{kg}$ de ração seguida pela carne das aves alimentadas com $3.000 \mathrm{kcal} \mathrm{EM} / \mathrm{kg}$. A quantidade de lipídios totais também foi maior na carne das aves alimentadas com rações contendo 2.600 e $3.000 \mathrm{kcal} \mathrm{EM/kg} \mathrm{de} \mathrm{ração.} \mathrm{Não} \mathrm{houve} \mathrm{influência} \mathrm{dos} \mathrm{níveis} \mathrm{de} \mathrm{energia} \mathrm{e} \mathrm{proteína} \mathrm{das}$ dietas nos parâmetros de desempenho e qualidade de carne. Conclui-se que os menores níveis de energia e de proteína na dieta não afetaram o desempenho, o rendimento de carcaça e a composição química da carne de codornas machos para postura.
\end{abstract}

Palavras-chave: Consumo de ração. Coturnix coturnix japônica. Produção de carne

\section{CARCASS YIELD AND MEAT QUALITY OF MALE LAYING QUAILS}

SUMMARY: The aim of this experiment was to evaluate performance of Japanese quail male subjected to different levels of energy and protein in the diet, and the carcass yield and chemical composition of meat. 216 quails were distributed on nine treatments, four replicates and six birds per cage. At 38 days the quails were distributed in a completely randomized design, factorial scheme 3x3, in three levels of metabolizable energy $(2,600 ; 2 ; 800$ and 3,000 $\mathrm{kcal} \mathrm{ME} / \mathrm{kg}$ ), and three levels of crude protein (16,18 and 20\%), composing the experimental diets supplied until 56

\footnotetext{
${ }^{1}$ Departamento de Agroecologia Professora Temporária do Centro de Ciências Agrárias/UFSCar, Rodovia Anhanguera, km174 CP 153 Araras - SP - Brasil, CEP13600-970

${ }^{2}$ Pós-Doutoranda do Programa de Zootecnia da Faculdade de Ciências Agrárias e Veterinárias/UNESP, Via de Acesso Prof. Paulo Donato Castellane, s/n, Jaboticabal - SP - Brasil, CEP 14884-900

${ }^{3}$ Doutora em Zootecnia

${ }^{4}$ Professor Adjunto do Centro e Educação Superior do Oeste/UDESC, Rua Beloni Trmbeta Zanin, 680 E, sala 21, Chapecó - SC - Brasil, CEP: 89815-630

${ }^{5}$ Pós-Doutorando do Programa de Zootecnia da Faculdade de Ciências Agrárias e Veterinárias/UNESP, Via de Acesso Prof. Paulo Donato Castellane, s/n, Jaboticabal - SP - Brasil, CEP 14884-900

${ }^{6}$ Pós-Doutorando do Programa de Zootecnia da Faculdade de Ciências Agrárias e Veterinárias/UNESP, Via de Acesso Prof. Paulo Donato Castellane, s/n, Jaboticabal - SP - Brasil, CEP 14884-900

${ }^{7}$ Professora Adjunto do Centro de Ciências Agrárias/UFSCar, Rodovia Anhanguera, km174 CP 153 Araras -SP Brasil, CEP13600-970

${ }^{8}$ Professora Adjunto da Faculdade de Ciências Agrárias e Veterinárias/UNESP, Via de Acesso Prof. Paulo Donato Castellane, s/n, Jaboticabal - SP - Brasil, CEP 14884-900

${ }^{9}$ Professora Adjunto da Faculdade de Ciências Agrárias e Veterinárias/UNESP, Via de Acesso Prof. Paulo Donato Castellane, s/n, Jaboticabal - SP - Brasil, CEP 14884-900
} 
days old. The results showed that the original dry matter was significantly higher in meat from quails subjected to treatment with $2,600 \mathrm{kcalME} / \mathrm{kg}$ followed by meat from quails fed with $3,000 \mathrm{kcalME} / \mathrm{kg}$. The quantity of total fat was also higher in meat from quails fed diets with 2,600 and 3,000 kcalME/kg. There was no influence of different levels of energy and protein of the diets on parameters of performance and quality of meat. We conclude that the lower levels of energy and protein in the diet did not affect the performance, carcass yield and meat chemical composition of Japanese quails male.

Keywords: Coturnix coturnix japonica. Feed intake. Meat production

\section{INTRODUÇÃO}

Atualmente, as codornas machos de postura são descartadas logo após o nascimento por não terem propósito na produção de ovos para consumo. Porém, a carne de codornas é muito apreciada sendo considerada exótica e com grande valor comercial, além de ser apresentada como um produto diferenciado, altamente palatável que permite vários tipos de processamentos, como a elaboração de conservas, defumados e assados (PANDA; SINGH, 1990).

Codornas apresentam crescimento rápido, ao nascer pesam entre 7,5 a 9,0g, dobram o peso em apenas quatro dias, triplicam-no aos oito e decuplicam-no aos 28 , enquanto que frangos de corte só dobram o peso ao nascer em torno dos oito ou nove dias (MURAKAMI; ARIKI, 1998). Devido a essa característica, é imprescindível que as exigências nutricionais de codornas sejam atendidas pela dieta.

Diversas pesquisas apontam a importância do nível protéico e energético sobre o ganho de peso, conversão alimentar e mortalidade, principalmente nas primeiras fases de vida (DARDEN; MARKS, 1988; OLIVEIRA et al., 2000).

Oliveira et al. (2000) recomendaram níveis de 24 ou 26\% PB para alimentação de machos de codorna japonesa, não especializados para corte, até os 28 dias e níveis de 18 a $20 \%$ PB desta idade até aos 45 dias.

De acordo com Murakami et al. (1993), codornas japonesas de ambos os sexos obtiveram melhor conversão alimentar com o aumento do teor de energia de 2.800 para $3.000 \mathrm{kcal} \mathrm{EM} / \mathrm{kg}$ de dieta. Já o NRC (1994) recomenda 2.900kcal EM/kg de dieta para atender às exigências de codornas japonesas nas fases inicial e de crescimento.

Rajini; Narahari (1998) compararam o desempenho de codornas de dupla aptidão alimentadas com rações contendo 24,26 e $28 \%$ de proteína no período de zero a três semanas, e 18, 20 e $22 \%$ no período de quatro a seis semanas, e níveis de energia metabolizável de $2.400,2.600$ e $2.800 \mathrm{kcal}$ $\mathrm{EM} / \mathrm{kg}$ em ambos os períodos, sendo os melhores resultados para ganho de peso e conversão alimentar obtidos com 28\% PB na ração inicial, substituída aos 21 dias por ração de crescimento contendo $22 \%$ PB, independentemente do nível energético. Os níveis de $28 \%$ de PB na fase inicial e $22 \%$ na fase final resultaram em maior rendimento de carcaça, maior porcentagem de proteína e menor porcentagem de gordura na carcaça, enquanto o maior nível de energia conduziu a um menor nível protéico e maior nível de gordura na carcaça. 
Quanto à qualidade da carne, a de codornas é reconhecida desde os povos mais antigos por seu alto conteúdo em proteínas e por sua escassa infiltração de gordura, aliada a rapidez de crescimento, proporcionando uma carne muito tenra, com preparação gastronômica fácil e rápida (DALMAU, 2002).

A carne de codorna é escura, macia e muito saborosa, além de ser excelente fonte de vitamina $\mathrm{B}_{6}$, niacina, $\mathrm{B}_{1}, \mathrm{~B}_{2}$, ácido pantotênico, bem como de ácidos graxos. Também apresenta grandes concentrações de ferro, fósforo, zinco e cobre quando comparada à carne de frango. O colesterol na carne de codorna atinge valores intermediários $(76 \mathrm{mg})$ entre a carne de peito $(64 \mathrm{mg})$ e da coxa e sobre-coxa $(81 \mathrm{mg})$ do frango. Porém, esses valores podem variar de acordo com a idade, sexo, linhagem e composição do alimento oferecido às aves (MORAES e ARIKI, 2000). Quanto aos aminoácidos essenciais, a carne de codorna é superior a de outras aves como o frango, a perdiz e o faisão (TABOADA, 1998).

O rendimento de carcaça é influenciado pelo teor de proteína bruta da dieta, demonstrando que dietas com alto teor de proteína, principalmente se associadas a um baixo nível de energia metabolizável, favorecem menor deposição de gordura na carcaça, melhorando o rendimento (RAJINI; NARAHARI, 1998). De acordo com a literatura o rendimento de carcaça de codornas pode variar de 57 a 74\% (MÓRI et al., 2005; OLIVERIA et al., 2005; SANTOS et al., 2006; SILVA et al., 2007; CORRÊA et al., 2008).

Dessa forma, este estudo teve como objetivo avaliar o desempenho, o rendimento de carcaça, a composição química e a qualidade de carne de codornas quando submetidas a diferentes níveis de energia e proteína na dieta.

\section{MATERIAL E MÉTODOS}

O experimento foi conduzido em galpão convencional para criação de codornas localizado no Setor de Avicultura do Departamento de Zootecnia da Faculdade de Ciências Agrárias e Veterinárias, Campus de Jaboticabal, UNESP.

As codornas foram criadas em piso até os 22 dias de idade, quando foram transferidas para gaiolas nas quais permaneceram até o abate. No período de 1 a 37 dias, as codornas macho foram alimentadas com ração composta por milho, farelo de trigo e farelo de soja, contendo $20 \%$ de PB e $2.800 \mathrm{kcal} \mathrm{EM} / \mathrm{kg}$.

Aos 38 dias de idade, 216 codornas macho, com peso médio de $110 \mathrm{~g}$, foram distribuídas em nove tratamentos, quatro repetições e seis aves por parcela. $\mathrm{O}$ delineamento experimental foi inteiramente casualizado distribuído em fatorial 3 x 3, sendo três níveis de energia $(2.600,2.800$ e $3.000 \mathrm{kcal} \mathrm{EM} / \mathrm{kg}$ ) e três níveis de proteína (16, 18 e 20\%). O balanceamento das rações seguiu as tabelas de composição de ingredientes proposta por Rostagno et al. (2005) e as exigências nutricionais recomendadas por Murakami et al. (1993). 
As aves receberam ração composta por milho e farelo de soja dos 38 aos 56 dias de idade, sendo essa fornecida três vezes ao dia e a água à vontade. Utilizou-se apenas luz natural.

Os parâmetros de desempenho analisados foram ganho diário em peso (GDP), consumo diário de ração (CDR) e conversão alimentar (CA).

Aos 56 dias de idade, oito aves de cada tratamento foram pesadas individualmente após jejum de oito horas, sacrificadas por deslocamento cervical e sangradas pela veia jugular. Em seguida foram pesadas, depenadas e evisceradas para a avaliação do rendimento de carcaça em relação ao peso do animal vivo.

Para a determinação da composição química e de qualidade de carne, quatro amostras de cada tratamento foram homogeneizadas em multiprocessador até a obtenção de uma massa homogênea, sendo todas as análises feitas em triplicatas.

Analisou-se para a composição química da carne a proteína bruta que foi quantificada pelo método de Kjeldahl, os lipídios totais (LT) extraídos pelo método de Soxhlet, a umidade determinada em estufa a $105^{\circ} \mathrm{C}$ até a obtenção de peso constante, e as cinzas em mufla a $550^{\circ} \mathrm{C}$. A umidade, cinzas e proteína foram realizadas segundo metodologia descrita por AOAC (1995) e os lipídios totais analisados pela metodologia descrita por Bligh; Dyer, com pequenas modificações feitas por Maxwell (1987).

Para a qualidade da carne analisou-se o $\mathrm{pH}$, a cor ( $\mathrm{L}$, a e b), as perdas por cozimento e a força de cisalhamento. Todas as análises foram realizadas em triplicata. $\mathrm{O} \mathrm{pH}$ foi determinado por meio de eletrodo de penetração no músculo Pectoralis major, a cor do músculo determinada pelo aparelho Minolta Chrome Meter, sendo obtido os parâmetros L* (luminosidade), a* (intensidade de vermelho) e $b^{*}$ (intensidade de amarelo).

As perdas por cozimento foram efetuadas segundo metodologia proposta por Cason et al. (1997), na qual as amostras de carne de peito cruas foram pesadas e embaladas, sendo em seguida transferidas para banho-maria a $85^{\circ} \mathrm{C}$ por $30 \mathrm{~min}$ para o seu cozimento a vapor. Após este procedimento, as amostras foram retiradas do banho, resfriadas em temperatura ambiente e novamente pesadas, onde a diferença entre o peso inicial e final das amostras correspondeu à perda de água na cocção. As amostras empregadas na determinação das PPC foram às mesmas utilizadas para avaliar a força de cisalhamento.

Para se determinar a força de cisalhamento das amostras de carne de peito cozidas utilizou-se o aparelho Texture Analyzer TA-XT2i acoplado à sonda Warner-Bratzler. Depois que as amostras de peito atingiram a temperatura ambiente após o cozimento, as mesmas foram cortadas em tiras de aproximadamente $1,5 \mathrm{~cm}$ de largura, apresentando em média $3 \mathrm{~cm}^{2}$ de área de corte, sendo colocadas com as fibras orientadas no sentido perpendicular às lâminas do aparelho Texture Analyser TA-XT2i acoplado ao dispositivo Warner-Bratzler pré-calibrado com um peso de $5 \mathrm{~kg}$, com velocidade de $5 \mathrm{~mm} / \mathrm{s}$ (Test speed) e distância percorrida para cortar a amostra de 35mm (Distance rupture test), determinando-se então a força máxima necessária para efetuar seu corte (LYON et al., 1998). 
As análises estatísticas dos resultados obtidos foram realizadas por meio do procedimento GLM do SAS ${ }^{\circledR}$ (STATISTICAL ANALYSIS SYSTEM INSTITUTE, 1995) e as médias comparadas pelo teste de Tukey $(\mathrm{P}>0,05)$.

\section{RESULTADOS E DISCUSSÃO}

Não houve diferença significativa entre os tratamentos para os resultados de desempenho e rendimento de carcaça (Tabela 1). O consumo de ração e a conversão alimentar geralmente são influenciados pela quantidade de energia na dieta, ou seja, quanto mais energia na dieta menor é o consumo e melhor é a conversão alimentar (MURAKAMI, 1991), porém, isso não ocorreu no presente trabalho.

TABELA 1: Valores médios obtidos para consumo diário de ração (CDR), ganho diário de peso (GDP), conversão alimentar (CA) e rendimento de carcaça.

\begin{tabular}{ccccc}
\hline CDR (g) & GPD (g) & CA & $\begin{array}{c}\text { Rendimento } \\
\text { carcaça (\%) }\end{array}$ \\
\hline $\begin{array}{c}\text { EM } \\
\text { (kcal/kg) }\end{array}$ & & & & \\
\hline 2600 & 16,86 & 2,29 & 7,38 & 77,44 \\
2800 & 16,24 & 2,15 & 7,47 & 76,56 \\
3000 & 16,04 & 2,28 & 7,16 & 77,49 \\
\hline P value & 0,1291 & 0,9517 & 0,6357 & 0,0866 \\
\hline PB (\%) & & & & 77,27 \\
\hline 16 & 16,45 & 2,31 & 7,14 & 77,72 \\
18 & 16,09 & 2,23 & 7,20 & 76,53 \\
\hline 20 & 16,61 & 2,17 & 7,62 & 0,3189 \\
\hline P value & 0,0778 & 0,3254 & 0,5540 & 1,18 \\
\hline EM x PB & 0,89 & 0,89 & 0,30 & 2,60 \\
\hline CV (\%) & 6,39 & 7,00 & 6,59 & \\
\hline
\end{tabular}

NS: P>0,05.

Oliveira et al. (2002) não observaram influência do nível protéico sobre o desempenho de codornas machos para corte.

Utilizando dietas com níveis protéicos que variaram de 20 a 26\% de PB, Murakami et al. (1993) não encontraram efeito significativo dos níveis de proteína sobre o consumo de ração de codornas japonesas de ambos os sexos, do nascimento aos 42 dias de idade.

Freitas et al. (2006) forneceram rações com níveis crescentes de proteína (20, 22, 24 e $26 \%$ de PB) e energia metabolizável $(2.565,2.715,2.865$ e $3.015 \mathrm{kcal}$ de $\mathrm{EM} / \mathrm{kg}$ ) para codornas de corte e verificaram que o aumento da EM diminuiu linearmente o consumo de ração. Já os diferentes níveis de proteína das rações não influenciaram o consumo de ração e o ganho de peso. 
Resultados para rendimento de carcaça semelhante aos do presente estudo foram descritos para codornas de corte macho criadas com diferentes níveis de proteína e energia na dieta (MÁS et al., 2004; MURAKAMI, 1991).

Silva et al. (2007) testaram diferentes níveis de proteína (24, 21,6 e 19,2\% de PB) na dieta de codornas macho para produção de carne e observaram que os níveis empregados não influenciaram o rendimento de carcaça. Do mesmo modo, Oliveira et al. (2005) não verificaram efeito dos níveis de proteína bruta $(20,22,24$ e $26 \%)$ da dieta sobre o rendimento de carcaça de codornas macho para corte abatidas aos 49 dias de idade.

As características químicas avaliadas não diferiram estatisticamente entre os níveis de proteína na dieta, porém, a matéria seca original foi significativamente mais elevada na carne das aves submetidas ao tratamento contendo $2.600 \mathrm{kcal} \mathrm{EM} / \mathrm{kg}$ de ração seguida pela carne das aves alimentadas com $3.000 \mathrm{kcal} \mathrm{EM} / \mathrm{kg}$. A quantidade de lipídios totais também foi maior na carne das aves alimentadas com rações contendo 2.600 e $3.000 \mathrm{kcal}$ EM/kg de ração (Tabela 2).

Os valores médios observados para matéria seca na carne de codornas macho para postura são semelhantes aos encontrados por Garcia et al. (2005) na carne de coxa $(28,14 \%)$ e peito $(28,12 \%)$ de frangos de corte alimentados com cinco níveis de sorgo em substituição ao milho.

A carne de codornas macho para postura apresentou valores superiores para cinzas quando comparada a de perdiz 1,4 e 1,2\% para carne proveniente da coxa e do peito sem pele, respectivamente (MORO et al., 2006) e de frango 1,01\% para coxa e 1,20\% para peito (GARCIA et al., 2005).

TABELA 2: Valores percentuais médios obtidos para matéria seca original (MSO), cinzas, proteína (PROT) e lipídios totais (LT) na matéria seca original.

\begin{tabular}{ccccc}
\hline & MSO & CINZAS & PROT. & LT \\
\hline $\begin{array}{c}\text { EM } \\
(\mathbf{k c a l} / \mathbf{k g})\end{array}$ & & & & \\
\hline 2600 & $29,96 \mathrm{a}$ & 1,66 & 27,88 & $2,96 \mathrm{a}$ \\
2800 & $27,21 \mathrm{~b}$ & 1,73 & 27,05 & $2,21 \mathrm{~b}$ \\
3000 & $28,31 \mathrm{ab}$ & 1,42 & 26,62 & $3,06 \mathrm{a}$ \\
\hline P value & 0,0136 & 0,3388 & 0,5886 & 0,0161 \\
\hline PB (\%) & & & & 2,91 \\
\hline 16 & 28,79 & 1,56 & 26,21 & 2,76 \\
18 & 28,44 & 1,89 & 27,57 & 2,55 \\
20 & 28,26 & 1,36 & 27,75 & 0,4875 \\
\hline P value & 0,8294 & 0,0665 & 0,4024 & 1,14 \\
\hline EM x PB & 0,82 & 1,66 & 0,38 & 26,57 \\
CV $(\%)$ & 7,49 & 33,75 & 1,07 & \\
\hline
\end{tabular}

Médias seguidas de mesma letra na mesma coluna não diferem entre si pelo Teste de Tukey (P>0,05). NS: $\mathrm{P}>0,05, * \mathrm{P}<0,05$. 
Os teores médios obtidos para proteína na carne de codornas foram semelhantes aos observados por Moro et al. (2006) na carne de perdiz (25,2 e 29,1\% para coxa e peito sem pele, respectivamente), valores estes superiores aos encontrados na carne de coxa $(23,83 \%)$ e peito $(19,35 \%)$ frangos (GARCIA et al., 2005).

De acordo com os dados obtidos na Tabela 3, pode-se notar que não houve diferença significativa $(\mathrm{P}>0,05)$ entre os parâmetros qualitativos da carne de codornas machos no que se refere aos níveis de energia e proteína utilizados.

Em relação ao pH da carne, observou-se médias entre 5,82 a 5,90, valor este semelhante ao da carne de frango, que é a carne de aves mais estudada, e possui pH entre 5,7 e 5,96, em condições normais (MENDES et al., 2003).

A respeito da cor da carne, notou-se tratar de carnes mais escuras que a carne de frangos, possuindo médias para luminosidade (L) de 35 e para intensidade de vermelho (a) de 17, contra L próximo de 47 e a (vermelho) de 3, segundo Komiyama et al., (2005). A intensidade de amarelo foi significativamente menor quando se utilizou $20 \%$ de $\mathrm{PB}$, diferenciado $(\mathrm{P}<0,05)$ da carne das aves que receberam $16 \%$.

Não houve influência dos fatores sobre a textura e perdas por cocção, sendo que os valores de textura foram próximos aos encontrados para frangos de corte (BOAIGO et al., 2005).

TABELA 3: $\mathrm{pH}$, cor, perdas de peso por cozimento (PPC) e força de cisalhamento em amostras de carne provenientes de codornas machos para postura. 0

\begin{tabular}{ccccccc}
\hline & $\mathbf{p H}$ & $\mathbf{L}$ & $\begin{array}{c}\text { Cor } \\
\mathbf{b}\end{array}$ & $\mathbf{a}$ & $\mathbf{P P C}(\%)$ & $\begin{array}{c}\text { Força } \\
\left(\mathbf{k g f} / \mathbf{c m}^{2}\right)\end{array}$ \\
\hline EM & & & & & & \\
\hline 2600 & 5,82 & 34,56 & 1,95 & 17,21 & 19,13 & 1429,25 \\
2800 & 5,90 & 35,03 & 2,07 & 17,02 & 16,21 & 1386,58 \\
3000 & 5,86 & 35,04 & 2,05 & 16,98 & 17,90 & 1415,14 \\
P value & 0,5485 & 0,8546 & 0,9527 & 0,8909 & 0,1097 & 0,8996 \\
\hline PB & & & & & & \\
\hline 16 & 5,88 & 35,62 & $2,57 \mathrm{a}$ & 17,70 & 18,11 & 1338,33 \\
18 & 5,82 & 35,13 & 2,04 ab & 16,86 & 16,89 & 1476,33 \\
20 & 5,88 & 33,86 & $1,45 \mathrm{~b}$ & 16,65 & 18,22 & 1416,58 \\
\hline P value & 0,6676 & 0,2020 & 0,0431 & 0,1140 & 0,5509 & 0,3560 \\
\hline EM x PB & 0,8721 & 0,6354 & 0,8980 & 0,7151 & 0,2688 & 0,3299 \\
CV(\%) & 3,01 & 6,89 & 50,89 & 7,31 & 18,48 & 16,41 \\
\hline
\end{tabular}

De acordo com os resultados obtidos no presente estudo, os níveis de $2600 \mathrm{kcal} \mathrm{EM} / \mathrm{kg}$ e $16 \%$ de proteína na dieta não afetaram o desempenho, o rendimento de carcaça, a composição química e a qualidade da carne de codornas machos para postura. 


\section{REFERÊNCIAS}

AOAC - Association of Official Analytical Chemists. Official methods of analyze. $16^{\text {th }}$ ed. Association of Official Analytical Chemists, Arlington, USA, 1094pp., 1995.

BOIAGO, M. M. et al.Características qualitativas da carne de peito de frangos de corte de linhagens tipo caipira criadas confinadas e semiconfinadas. Revista Brasileira de Ciência Avícola, n.7, p.148, 2005.

CASON, J. A.; LYON, C. E.; PAPA, C. M. Effect of muscle opposition during rigor on development of broiler breast meat tenderness. Poultry Science, n.76, p.785-787, 1997.

CORREAA, G. S. S. et al. Nível de proteína bruta para codornas de corte durante o período de crescimento. Arquivo Brasileiro de Medicina Veterinária e Zootecnia, v.60, n.1, p.209-217, 2008.

DALMAU, A. B. Sistemas produtivos de codornices. I Simpósio Internacional de Coturnicultura, Lavras, Brasil, p.49-65, 2002.

DARDEN, J. R.; MARKS, H. L. Divergent selection for growth in Japanese quail under split and complete nutritional environments. 2. Water and feed intake patterns and abdominal fat and carcass lipid characteristics. Poultry Science, n.67, p.1111-1122, 1998.

FREITAS, A. C.et al. Níveis de proteína bruta e energia metabolizável na ração para codornas de corte. Revista Brasileira de Zootecnia, v.35, n.4, p.1705-1710, 2006.

GARCIA, R. G. et al.Desempenho e qualidade da carne de frangos de corte alimentados com diferentes níveis de sorgo em substituição ao milho. Arquivo Brasileiro de Medicina Veterinária e Zootecnia, v.57, n.5, p.634-643, 2005.

KOMIYAMA, C. M. et al. Efeito do tempo de jejum e banho de aspersão sobre as características de qualidade de carne de frangos de corte. Conferência Apinco de Ciência e Técnoligia Avícola, Santos/SP, Brasil, p.173, 2005.

LYON, C. E.; LYON, B. G.; DICKENS, J. A. Effects of carcass stimulation, deboning time, and marination on color and texture of broiler breast meat. Journal of Applied Poultry Research, v.7, n.1, p.53-60, 1998.

MÁS, H.et al. Rendimento de carcaça de codornas de corte submetidas a diferentes níveis protéicos e idades de abate. II Simpósio Internacional e I Congresso Brasileiro de Coturnicultura, Lavras, Brasil, p.206, 2004.

MAXWELL, R. J. Determination of total lipid and lipid sub classes in meat and meat products. Association of Official Analytical Chemists Journal, n.70, p.74-77, 1987.

MENDES, A. A.; MOREIRA, J.; GARCIA, R. G. Qualidade da carne de peito de frango de corte. Revista Nacional da Carne, v.28, n.317, p.138-144, 2003.

MORAES, V. M. B.; ARIKI, J. Importância da nutrição na criação de codornas e qualidades nutricionais do ovo e carne de codorna. III Reunião Itinerante de Fitossanidade do Instituto Biológico, Mogi das Cruzes, Brasil, p.193-204, 2000.

MÓRI, C.; GARCIA, E. A.; Pavan, A. C.; PICCININ, A.; PIZZOLANTE, C. C. Desempenho e rendimento de carcaça de quatro grupos genéticos de codornas para produção de carne. Revista Brasileira de Zootecnia, v.34, n.3, p.870-876, 2005. 
MORO, M. E. G.et al. Rendimento de carcaça e composição química da carne da perdiz nativa (Rhynchotus rufescens). Ciência Rural, v.36, p.258-262, 2006.

MURAKAMI, A. E. Níveis de proteína e energia em dietas de codornas japonesas (Coturnix coturnix japonica) nas fases de crescimento e postura. Tese de Doutorado, Universidade Estadual Paulista, Brasil, 92pp., 1991.

MURAKAMI, A. E.; ARIKI, J. Produção de codornas japonesas. Funep, Jaboticabal, Brasil, 79pp., 1998.

MURAKAMI, A. E. Et al. Níveis de proteína e energia em rações para codornas japonesas (Coturnix coturnix japonica) em crescimento. Revista Brasileira de Zootecnia, v.22, p.534-540, 1993.

NRC - National Research Council. Nutrient requirements of poultry. $9^{\text {th }}$ ed. National Academy Press, Washington, USA, 156pp., 1994.

OLIVEIRA, E. G.et al. Avaliação do rendimento de carcaça de codornas para corte alimentadas com dietas com diferentes níveis protéicos. Archives of Veterinary Science, v.10, n.3, p.42-45, 2005.

OLIVEIRA, N. T. E. et al. Exigências de energia e proteína para codornas japonesas machos criadas para a produção de carne. Anais da $37^{\mathrm{a}}$ Reunião Anual da Sociedade Brasileira de Zootecnia, Viçosa, Brasil, p.37, 2000.

PANDA, B.; SINGH, R. P. Developments in processing quail meat an eggs. World's Poultry Science Journal, v.46, n.11, p.219-234, 1990.

RAJINI, R. A.; NARAHARI, D. Dietary energy and protein requirements of growing japanese quails in the tropics. Indian Journal of Animal Sciences, v.68, n.10, p.1082-1086, 1998.

ROSTAGNO, H. S. et al. Tabelas brasileiras para aves e suínos: composição de alimentos e exigências nutricionais de aves e suínos. $2^{\mathrm{a}}$ ed. UFV, Viçosa, Brasil, 186pp., 2005.

SANTOS, A. L. S. et al.Níveis de inclusão de farinha de penas na dieta sobre o desempenho e características de carcaça de codornas para corte. Acta Scientiarum. Animal Sciences, v.28, n.1, p.2730, 2006.

SILVA, E. L.et al. Efeito do plano de nutrição sobre o rendimento de carcaça de codornas tipo carne. Ciência Agrotécnica, v.31, n.2, p.514-522, 2007.

STATISTICAL ANALYSIS SYSTEMS INSTITUTE. User's guide. Version $6.4^{\text {th }}$ ed. SAS ${ }^{\circledR} /$ STAT, SAS Institute Incorporation, Cary, USA, 365pp., 1995.

TABOADA, P. Efectos del sexo sobre los rendimientos en la codorniz japonesa (Coturnix coturnix japonica) y la composición química de su carne. Revista Cubana de Ciencia Avícola, v.22, p.19-24, 1998. 
